\title{
INTERMODAL TRANSPORTATION OF DANGEROUS GOODS
}

\begin{abstract}
The paper deals with intermodal transportation, broadly defined as a chain consisting of several transportation modes that are coordinated and interact in intermodal terminals to ensure door-to-door service. The goal of the article is to describe the road-sea intermodal flow, to define the responsibilities of each party of a transportation chain and to identify important issues and bottlenecks in the whole intermodal transportation. Recently, the demand for the transportation of dangerous goods has been rising. Transport of dangerous goods can have serious effects on the environment if an accident happens. The legal environment for each transport department, harmonisation of the rules and regulations for intermodal transportation and setting the responsibilities for every party of the transportation chain (such as forwarder, hauler, shipper and consignor) make the transports of dangerous goods more safe and efficient and can reduce risks and threats.
\end{abstract}

Keywords: Intermodal, transport, dangerous goods, agreement.

\section{Introduction}

European Conference of Ministers of Transport (ECMT) defines intermodal transport as the movement of freight in one and the same loading unit or vehicle which uses successive, various modes of transport (road, rail, water) without any handling of goods themselves in changing modes [1].

Intermodality provides the economic performance of the transport chain by using different modes in the most productive manner. Many characteristics influence the intermodal transport chain:

- quantity and the nature of transported cargo,

- the sequence of transportation modes - the leading modes are lorries, rails and vessels (inland waterway or maritime). Air transportation is usually not used in the combination with other modes,

- places of origin and destination - the longer the transport distance, the more transportation modes are used,

- the value of the goods - high value shipments are usually transported by air, while low and intermediate shipments are usually transported by rail and inland waterways,

- frequency of shipments [1].

Intermodal transport combines the advantages of the individual modes of transport involved, namely the large capacity and relative speed of rail transport, the flexibility of road transport and the advantageous price and high capacity of water transport [2]. Another advantage is the provision of a service with one bill of lading (for cargo) or one ticket (for passengers). This caused a revolution in organisation and information controlling. In present days, data are received, handled and distributed to the systems, which are essential to ensure the safe and cost-effective control of cargo and passenger movements. Electronic Data Interchange (EDI) is an evolving technology, which helps companies and government agencies to deal with the increasing global transport system [3].

Due to dangerous characteristics of the hazardous goods there are many risks in addition to those normally associated with general transport activities. According to the data of databases with information on dangerous transportations (US Department of Hazardous Material Transportation Information system 4) it is clear that more than half of the total number of incidents occur during the activities at the transport hubs and nodes. In general, there exist different regulations governing dangerous transports by inland waterways, rail and roads, but in practice, the regulation of the whole intermodal transport of dangerous goods (DG) does not exist. The rules for safe international transport of dangerous goods (ADR, RID, AND, IMDG) ensure safety of the DG transports, reliability and functioning of the common transport market. Even though the regulations for every inland transport mode are harmonised (by the Directive 2008/68/EC of the European Parliament and of the Council), there is still area for improvement [4].

\footnotetext{
* Andrea Galierikova, Jarmila Sosedova

Department of Water Transport, Faculty of Operation and Economics of Transport and Communications, University of Zilina, Slovakia E-mail: andrea.galierikova@fpedas.uniza.sk
} 
2. Legal environment for transportation of dangerous goods

The aim of DG regulations and rules is to prevent negative impacts on human life, property and the environment. In addition, the regulations also focus on facilitating trade and the efficient and safe transportation of dangerous goods.

$A D R$ is the European Agreement concerning the International Carriage of Dangerous Goods by Road. The aim of ADR is to increase the safety of international transport by road. ADR consists of the list of dangerous goods, their classification, standards for marking, labelling and packaging of DG and also all types of packaging that can be used, transport equipment (vehicles, construction and equipment), training of drivers, emergency procedures, loading and unloading of cars [5].

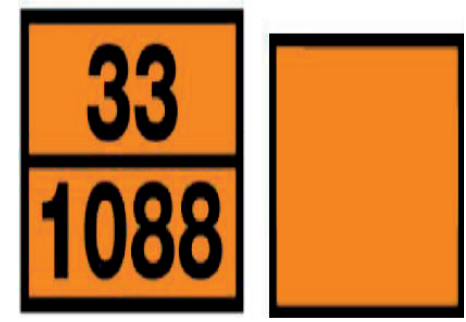

Fig. 1 The sign for labelling of the petroleum

Source: https://www.unece.org/trans/danger/publi/adr/adr_e.html

ADR establishes that every dangerous substance must be labelled with the sign containing Hazard Identification Number (HZI) and UN number (Fig. 1). The main advantage of using the UN number is that confusing similar names are removed and language barriers can be overcome. HZI includes two or three numbers representing the degree of danger. The first number shows the primary danger and also classification.
The second number presents the extent of possible hazard (usually is either a zero or a repeating number of the first one). The HZI is displayed on the top row of an orange sign that has to be on the lorry or container which contains dangerous goods. The second row of the orange sign includes the UN number [6].

Dangerous goods with their hazardous properties (such as explosiveness, corrosiveness, toxicity, flammability and radioactivity) are classified into nine classes according to the UN Recommendations on the Transport of Dangerous Goods Model Regulations (Table 1).

- RID presents the Regulations concerning the International Transport of Dangerous Goods by Rail. RID was drawn up by intergovernmental Organisation for International Carriage by Rail (OTIF), comprising 46 member countries. It is established on European territory through European directive 20008/68/EC. To ensure safety and protect the environment, RID sets out a list of hazardous goods which may be carried from loading to delivery place [7]. RID sets out the safety rules for shipper and carrier of dangerous goods which cover: safety measures to be taken during loading and unloading of goods,

- the full range of checks to be made prior to wagon departure, - information about the transport itself: the driver must know the contents of the load and the degree of hazard it presents, and wagons must carry information plates stating the nature of the goods and how hazardous they are,

parking and transport conditions

steps to be taken in the case of accidents or incidents [8]

- $A D N$ (The European Agreement concerning the International Carriage of Dangerous Goods by Inland Waterways) consists of the agreement and annexed Regulations, which aims to:

Classification of dangerous goods

Table 1

\begin{tabular}{|l|l|}
\hline Class & Examples \\
\hline 1 explosives & pyrotechnic material, munitions \\
\hline 2 gases & oxygen, helium, cigarette lighters \\
\hline 3 flammable liquids & petroleum products, alcoholic beverages \\
\hline 4.1 flammable solids & matches, celluloid \\
\hline 4.2 substances liable to spontaneous combustion & phosphorus, fish meal \\
\hline 4.3 substances emitting flammable gases (with water) & metal powders \\
\hline 5.1 oxidising substances & hydrogen peroxide \\
\hline 5.2 organic peroxides & plastic adhesive \\
\hline 6.1 toxic substances & insecticide, pesticides \\
\hline 6.2 substances liable to cause infections & medical wastes \\
\hline 7 radioactive material & uranium metal, nuclear fuel \\
\hline 8 corrosives & car batteries, sulphuric acid \\
\hline 9 miscellaneous dangerous substances & environmentally hazardous substances, mobile phones \\
\hline
\end{tabular}

Source: http://www.unece.org/?id=3598 
- ensuring safety of international carriage of dangerous goods by inland waterways,

- contributing to the environment protection by preventing any pollution resulting from incidents or accidents during DG carriage,

- facilitating transport operations,

- promoting international trade in dangerous goods [9].

$A D N$ contains rules for packaging of goods, requirements for the construction and operation of vessels for DG transportation. There are also rules for inspections, issue of approval certificates, recognition of classification societies, monitoring and training of experts.

- $I M D G$ or the International Maritime Dangerous Goods was developed by the International Maritime Organisation (IMO), which is a United Nations specialised agency. IMO deals with two key points for maritime industry: the safety of life at sea and prevention of pollution from ships. The IMO has created two international conventions: the MARPOL Convention (covering pollution prevention) and the SOLAS Convention (covering safety of life at sea).

The International Maritime Dangerous Goods (IMDG) Code was created as a uniform international code for maritime transport of dangerous goods which establishes requirements for packing, container traffic and stowage with reference to the separation of incompatible substances [10]. The aim of IMDG Code is to:

- ensure the safe DG transport

- protect environment and sea from negative impacts

- facilitate the free unrestricted DG movement.

Dangerous goods in IMDG Code have the same classes as in the UN Recommendation, so shipper is able to classify dangerous goods based on the 9 hazard classes, and the labels are internationally accepted [11]. Dangerous goods are uniquely identified by the UN Number and the corresponding PSN (Proper Shipping Name). This number enables quick and precise identification of the designated dangerous goods in the transport chain for correct stowage, handling and separation and also assists in the terms of the emergency.

\section{The road-sea intermodal flow}

In the intermodal transport of DG in combination of road and sea, the following parties are usually associated: consignor, forwarder, hauler, shipping company and a port (Fig. 2). The police and the coast guard are providing random checks and controls. The forwarder and the consignor have a contract which contains terms that are more restrictive than those in the case of goods which are not dangerous. A forwarder also has contracts with haulers and shipping companies. The shipping companies have contracts with the ports, containing loading, unloading and leasing of parking place. The contract relationships describe the forwarder as a party that has a whole responsibility of the dangerous goods for all the transport chain [11]. These responsibilities are presented by different sub-contractors, namely shipping companies and haulers. Basically, forwarding companies have no specific duties and operate more like coordinators between consignor and transport parties.

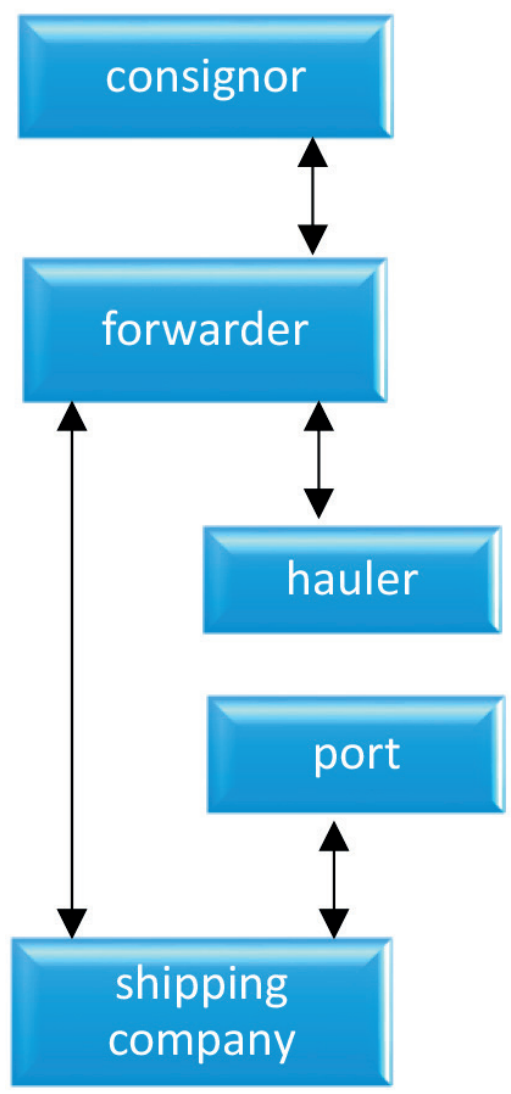

Fig. 2 Intermodal flow of $D G$ Adjusted data from [11]

The flow begins at the consignor with an order which is sent to transport company or to a forwarder (Fig. 3). The order is mostly made by phone or email. At first the forwarder receives the order, next he checks, if the order contains the important information such as UN-number, class, packaging group. Then the order of a road or sea transport is carried out. Orders from forwarding companies are usually sent by EDI (for big companies), email or phone (for small companies).

The consignor must verify whether the dangerous goods has approved labelling, marking and packaging. In the terms of rail transport, according to the RID regulation the consignor is responsible for the dangerous goods during whole transport. 
When the hauler arrives at the consignor and the driver is present, he is responsible to verify that the loading and lashing are done rightly and also check that the documents from the consignor are correct. ADR establishes that the driver is responsible to deliver the original document to the next transport party in the transport chain. The driver is also responsible for giving information to next transport party of the transport chain on what kind of DG is transported [11].

The responsibility moves from the consignor to the hauler when the dangerous shipment is loaded onto the lorry and the documents are signed. When the lorry arrives and unloads the shipment at the forwarder's terminal, the responsibility moves to the forwarder until the shipment is reloaded and driven out of the terminal. The driver of the lorry is responsible for appropriate labelling before the transport starts. After loading the trailer, the lorry driver transports it to the port. The responsibility moves to the hauler again. When the trailer is parked in the port area, the hauler's task is finished. Information about DG is sent from the forwarder to the shipping company a couple hours before the trailer arrives. As the lorry driver unloads the DG shipment and signs all documents, he can pass the gate with a card that was given to him. When the lorry goes through the gate, it is photographed by circa twenty cameras [11].
The responsibility moves from the hauler to the port since the trailer passes the port's gate and the responsibility of the port will last until the trailer is loaded on the ship. The driver of the trailer must deliver the documents to the shipping company. The requirements for delivery of the documents depend on the different shipping companies. The driver must report the exact location of the parked trailer and its parking number.

Ships that will arrive at the port must notify the port 24 hours before arrival. The shipping company cannot start to plan the loading until all the documents of dangerous goods have arrived. The documents can be an electronic copy or a fax copy. Every shipping company has different requirements for loading process. The port uses a special type of vehicles called tug masters to move the trailers within the port area and drivers who are responsible for loading the trailers on the ships. These drivers get information concerning what kind of dangerous goods will be handled [12].

Most of the dangerous goods can be shipped with "normal" cargo. Commonly the shipping companies do not place any dangerous goods near the safety boats or living places on the ship. Dangerous shipments are often placed on the top deck of the vessel.

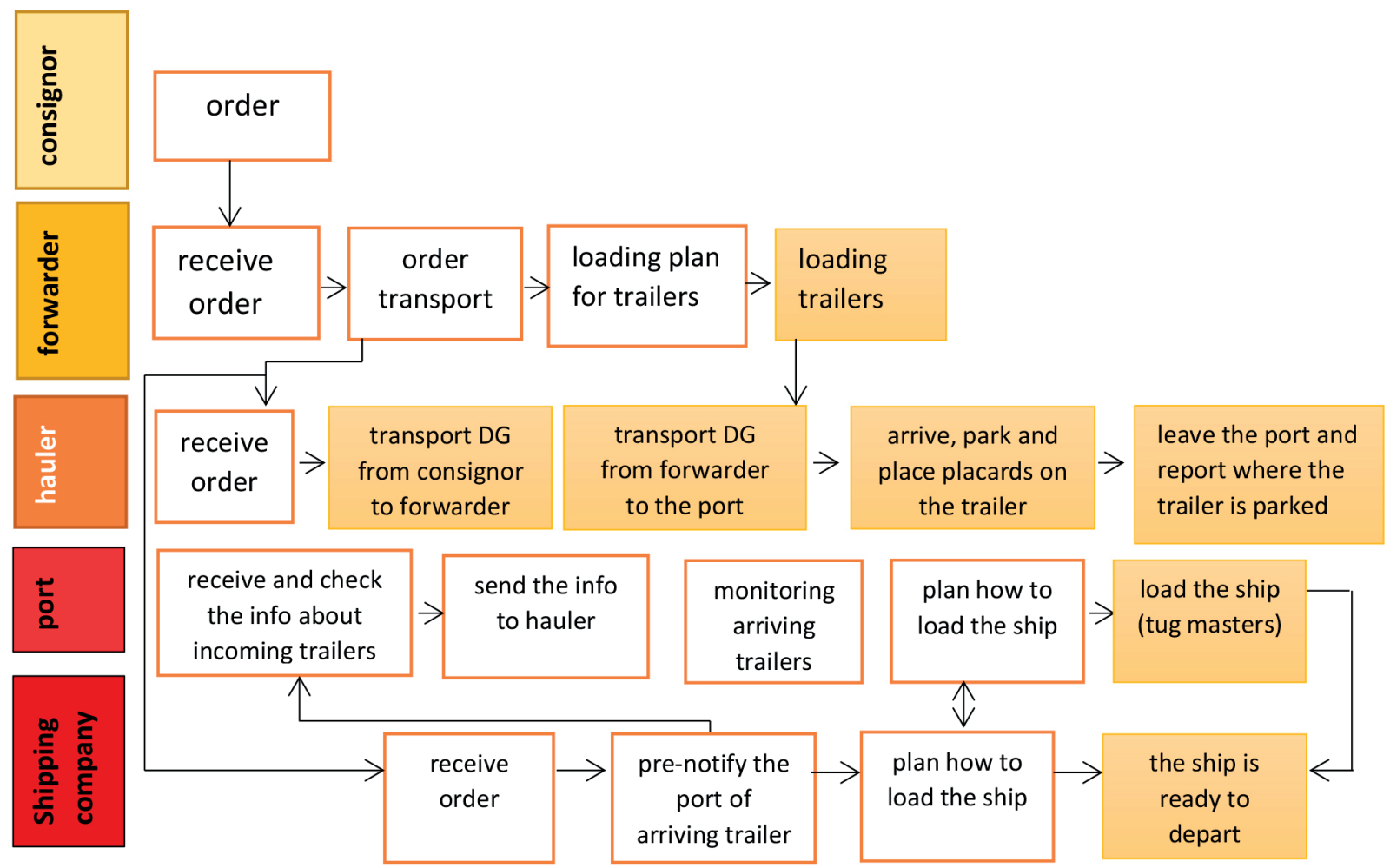

Fig. 3 General flow of $D G$

Source: adjusted data from [11] 


\section{Problems in the flow of dangerous goods}

Acknowledgement of DG handling is a problem for the parties that do not often deal with the transportation of dangerous goods. According to the data from Eurostat, in the road transport of DG, $90 \%$ of the accidents are caused by human fault, and it refers to the lorry drivers. The dirty and old labels are also a quite common problem (Fig. 4).

If the trailer is used for transportation of one type of dangerous goods all the time, the old and void labels can be used. The most common problem identified by shipping companies is wrong labelling of the units. Sometimes the drivers forget to place one or more labels on the trailer, or labels don't stick to the trailer and fall off due to bad weather [11].

For rail transport of dangerous shipments, missing placards are the most common problem. The rail transport of DG cannot be realised without placards. If an incident occurs during the transport, a rail company is not responsible for the shipment. According to the RID, the consignor is responsible for the goods during the transport [13].

Another possible risk is when the DG in the unit is not properly lashed. When the loading, stowing and securing of the dangerous shipment is not safe, the emergency during the handling and transportation can occur.

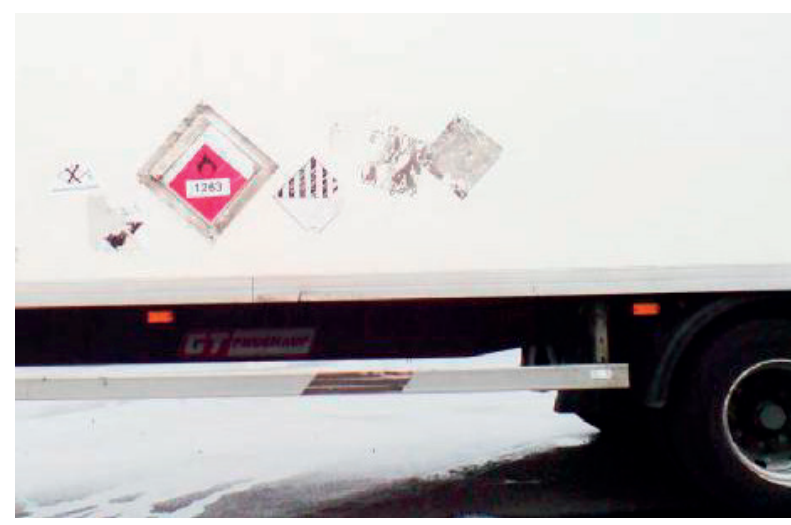

Fig. 4 Old labels

Source: https://gupea.ub.gu.se/bitstream/2077/20851/1/ gupea_2077_20851_l.pdf

\section{Problems at the interfaces}

The drivers have knowledge they need to safely load and unload dangerous goods, but the time and stress are the most common reasons for the mistakes. Leakage is another common emergency. A technical character of the lorry is often a reason. Because the loading is usually driver's responsibility, the hauler's company is the one who is responsible for a possible accident occurring during the loading. Problems also may occur if different types of dangerous goods with different UN number are loaded together (called mixed DG transport). The consignor often plans how to load different classes together, but sometimes he might be wrong and recognise the problem very late. Then the driver has to reload it again. Trailers with dangerous shipments are often arriving late to the port. The reason for this situation are unrealistic or exaggerated haulers' estimates, which consider planned transport times longer or equal to actual transport times. Some hauler companies also proclaim that they can deliver the goods within a certain time just to get more customers or to be able to provide better services [11].

\section{Conclusion}

As the worldwide supply and demand chains expand, there is a need for a good-working logistic system which provides quick procurement, production, distribution and faster delivery to the customers. To ensure safe and efficient intermodal system, several steps must be followed. The first step is to make the accurate plan of the transportation. The flow begins at the consignors' order. All important elements such as the UN number, packaging group must be correct. In the terms of DG transportation, the proper labelling and packaging are necessary. Each party of the transportation chain must know its responsibilities. Another crucial step is to detect the bottlenecks. Most of the problems that occur in the intermodal transportation of dangerous goods are due to human mistake. For this reason, the education of drivers and haulers in the terms of legal environment, documents and correct and current labelling is very important.

To know and observe the legal environment for DG transportation is another significant point. Although the rules and regulations concerning dangerous goods exist for individual transport modes, there is no rule for intermodal transports. Improved implementation and better harmonisation of rules together with reducing the problem areas in the transport interfaces will not only ensure the safety of dangerous goods transports but will also improve the transport efficiency due to the decreased number of accidents that improved security would lead to. 


\section{References}

[1] European Commision of Ministers of Transport. Terminology on combined transport www.unece.org. Available at: http:// www.unece.org/fileadmin/DAM/trans/wp24/documents/ term.pdf (18. 11 2016).

[2] RODRIGUE, J., SLACK, B.: The Geography of Transport Systems. London : Routledge 2012.

[3] LIZBETIN, J., CAHA, Z.: Theoretical Criteria for The Evaluation of the Operational Performance of Intermodal Transport Terminals, World Multidisciplinary Civil Engineering-Architecture-Urban Planning Symposium (WMCAUS), vol. 161, $1197-$ 1203, 2016, Prague.

[4] KUBANOVA, J., SCHMIDT, C.: Multimodal and intermodal transportation systems Communications - Scientific Letters of the University of Zilina, vol. 18, No. 2, 2016, 104-108, ISSN 1335-4205.

[5] The European Parliament and the Council of the EU. Directive 2008/68/EC. Available at: eur-lex.europa.eu: http://eur-lex. europa.eu/legal-content/EN/TXT/HTML/?uri=CELEX: 32008L0068\&from=EN (30. 11 2016)

[6] ADR applicable as from 1 January 2015 Available at: https://www.unece.org/trans/danger/ publi/adr/adr_e.html (2. 12 2016)

[7] RID - Convention concerning international Carriage by Rail. Available at: http://www.otif. org/fileadmin/user_upload/ otif_verlinkte_files/07_veroeff/99_geschuetzt/RID_2015_e/RID\%202015\%20E.pdf (2. 12 2016).

[8] BABIN, M., BUDA, M., MAJERCAK, J.: Terminals for Transportation of Dangerous Goods, Transport Means, $16^{\text {th }}$ Intern. Conference on Transport Means, Lithuania, 2012

[9] ADN applicable as from 1 January 2015.UN. www.unece.org. Available at: https://www.unece.org/trans/danger/publi/adn/ adn_e.html (2. 12 2016).

[10] IMO: International Maritime Dangerous Goods (IMDG) Code. Available at: https://law.resource.org/pub/us/cfr/ibr/004/ imo.imdg.1.2006.pdf (2.11.2016)

[11] SVENSSON, C., WANG, X.: Secure and Efficient Intermodal Dangerous Goods Transport, Master Degree Project, Secure and Efficient Intermodal Dangerous Goods Transport : Gothenburg, 2009.

[12] SULGAN, M., SOSEDOVA, J.: Rationalization of Internal Transport Operation in the Intermodal Transport Terminals, Communications - Scientific Letters of the University of Zilina, vol. 18, No. 2, 2016, 5-10, ISSN 1335-4205.

[13] UNECE secretariat: Transport of Dangerous Goods - Sixteenth OSCE Economic and Environmental Forum, Prague, May 2008. 